\title{
Mediatisasi Kebijakan Penerbitan E-Journal dengan Open Journal System di Indonesia
}

\author{
Wahid Nashihuddin \\ Pusat Data dan Dokumentasi Ilmiah - LIPI \\ Sekolah Pascasarjana, Universitas Gadjah Mada Yogyakarta \\ Email: wahed87@gmail.com; wahidnashihuddin@mail.ugm.ac.id
}

\begin{abstract}
Every technology and media carries its message for users and brings change in human life, including e-journal publishing. The practice of modernization in the e-journals publishing by OJS also has an impact on changing the journal appearance and the publishing process, starts from the manuscript submission by the author, editorial, and peer-reviewed, to journal publishing by the editor. Printed journals that are formed of paper sheets and have limited information access are different from e-journals that are formed of digital files and information access is not limited (online). The government policies regarding the OJS existence and function as one of the standard ejournal publishing platforms in Indonesia and the accreditation requirements of national scientific journals, also have an impacted on the behavior and culture-changing of the users (writers, editors, reviewers, proofreaders) and enhancing the scholarly communication culture. OJS as technology or media has become a mediation for its users and has even been institutionalized by the government, and this phenomenon has become one of mediation in journal publishing. This paper aims to find out the mediation of government policies related to the issuance of e-journals using OJS in Indonesia. The study data is descriptive-qualitative, with the source of literature study data and the best practice knowledge of the author. This study shows that government policies related to the use of OJS for e-journal publishing in Indonesia effect on changes in the appearance and process of journal publishing, changes in user behavior and culture, and improvement in scholarly communication culture.
\end{abstract}

Keywords: Mediatization; E-Journal; Open Journal System; Policies Government; Scholarly Communication

\begin{abstract}
Abstrak
Setiap teknologi dan media membawa pesan tersendiri bagi pengguna dan membawa perubahan dalam kehidupan manusia, termasuk dalam penerbitan e-journal. Praktik modernisasi dalam penerbitan e-journal dengan OJS juga
\end{abstract}


berdampak pada perubahan tampilan jurnal dan proses penerbitan, yang dimulai dari penyerahan naskah oleh penulis, editorial dan peer-review naskah, hingga penerbitan jurnal oleh editor. Jurnal cetak yang hanya berupa lembar kertas dan akses informasinya terbatas berbeda dengan $e$-journal yang berbentuk file digital dan akses informasinya tidak terbatas (online). Kebijakan pemerintah terhadap eksitensi dan fungsi aplikasi OJS sebagai salah satu platform standar penerbitan e-journal di Indonesia dan persyaratan akreditasi jurnal ilmiah nasional, juga berdampak pada perubahan perilaku dan kultur penggunanya (penulis, editor, reviewer, proofreader) serta peningkatan budaya komunikasi ilmiah. OJS sebagai teknologi atau media sudah menjadi mediasi bagi penggunanya dan bahkan sudah dilembagakan oleh pemerintah, dan fenomena tersebut menjadi salah satu mediatisasi dalam penerbitan jurnal. Tulisan ini bertujuan untuk mengetahui mediatisasi kebijakan pemerintah terkait penerbitan e-journal menggunakan OJS di Indonesia. Data kajian bersifat deskriptif-kualitatif, dengan sumber data studi literatur dan pengetahuan best practice penulis. Kajian ini menunjukkan bahwa kebijakan pemerintah terkait penggunaan OJS untuk penerbitan $e$ journal di Indonesia berpengaruh terhadap perubahan tampilan dan proses penerbitan jurnal, perubahan perilaku dan kultur pengguna, dan peningkatan budaya komunikasi ilmiah.

Kata kunci: Mediatisasi; E-Journal; Open Journal System; Kebijakan Pemerintah; Komunikasi Ilmiah

\section{A. PENDAHULUAN}

Perkembangan teknologi informasi dan komunikasi yang sangat cepat dalam dunia pendidikan dan penelitian berdampak pada pesatnya perkembangan ilmu pengetahuan dan teknologi (iptek) dalam dunia penerbitan, dan salah satunya adalah penerbitan jurnal elektronik (e-journal). Jurnal adalah salah satu terbitan berkala ilmiah yang terbit secara teratur dan memiliki bidang keilmuan tertentu. Jurnal ilmiah adalah bentuk pemberitaan atau komunikasi yang memuat karya ilmiah dan diterbitkan berjadwal dalam bentuk elektronik dan/atau tercetak (Kemenristekdikti, 2018). Jurnal ilmiah bersumber dari hasil penelitian atau kajian yang diterbitkan secara berkala, apakah bulanan, triwulan, semester, atau tahunan. Adapun fungsi jurnal yakni sebagai media informasi dan komunikasi antara penulis dengan pembaca.

Melalui jurnal, penulis dapat menyampaikan segala ide, pemikiran, dan pengetahuan dari hasil penelitiannya secara eksplisit tanpa ada intervensi dari siapapun. Kemudian pembaca, ia dapat menikmati dan mencermati setiap isi artikel jurnal, jika tertarik pada isi artikel maka dapat mengutipnya untuk 
bahan penulisan. Jurnal juga menjadi salah satu media komunikasi ilmiah (scholarly communication) bagi pihak-pihak yang terlibat dalam proses penerbitan, seperti penulis, editor, editor bagian, reviewer, copy editor, layout, editor, dan proofreader - mereka bertanggung jawab atas kualitas dan kuantitas jurnal yang diterbitkan (Lukman, Hidayat, \& Atmaja, 2016). Dalam proses komunikasi ilmiah ada aktivitas bertukar pikiran atau ide untuk mendiskusikan hasil penelitiannya (De Silva \& Vance, 2017).

Sejak diberlakukannya Surat Edaran Dirjen-DIKTI No.2050/E/T/2011 tentang Kebijakan Unggah Karya Ilmiah dan Jurnal; Surat Edaran DirjenDIKTI No. 152/E/T/2012 tentang Publikasi Karya Ilmiah S1 di Jurnal Nasional, S2 di Jurnal Nasional Terakreditasi, dan S3 di Jurnal Internasional. Kewajiban publikasi yang sudah diatur bagi dosen dan peneliti diharapkan dapat mendorong peningkatan jumlah dan mutu publikasi ilmiah pada tingkat nasional dan internasional sehingga Indonesia mampu bersaing dengan bangsa-bangsa lain (Lukman, Ahmadi, Manalu, \& Hidayat, 2017). Kemudian diikuti oleh Surat Edaran Dirjen-DIKTI No. 212/E/T/2012 tentang Panduan Pengelolaan Jurnal Terbitan Berkala Ilmiah Elektronik; dan Surat Edaran Dirjen Risbang-DIKTI No.93/E/SE/XII/2015 tentang Akreditasi Jurnal Ilmiah Secara Elektronik, pemerintah menetapkan kebijakan bahwa mulai 1 April 2016, akreditasi jurnal ilmiah nasional hanya berlaku untuk jurnal yang telah dikelola secara elektronik dengan platform Open Journal System (OJS) agar proses penilaian lebih mudah, cepat, akurat dan transparan. Jurnal yang telah diterbitkan secara elektronik kemudian didaftarkan pada database Akreditasi Jurnal Nasional (ARJUNA). Adanya kebijakan tersebut, maka setelah 1 April 2016, para pengelola/penerbit jurnal di Indonesia harus mematuhi segala persyaratan/ketentuan dalam penerbitan e-journal agar terbitannya dapat terakreditasi secara nasional.

Kebijakan pemerintah terkait penggunaan OJS sebagai platform standar penerbitan e-journal di Indonesia dan persyaratan akreditasi jurnal ilmiah nasional, maka setiap institusi (penerbit/afiliasi) dan pengguna harus memahami persyaratan teknis dan manajerial untuk mengoperasionalkan sistem tersebut, termasuk melengkapi fitur dan informasi kebijakan penerbitan di website jurnal. Mereka harus mengatur tampilan web jurnal (fitur dan menu) serta menyesuaikan cara kerja platform OJS untuk penerbitan jurnal, yang dimulai dari penulis menyerahkan naskah (manuscript submission), reviewer menelaah naskah (peer-review), hingga editor menerbitkan (publish) artikel di web jurnal. Setelah sistem di atur, aplikasi OJS ini akan mengubah tampilan dan proses penerbitan jurnal secara keseluruhan (dari jurnal cetak ke elektronik) tanpa membedakan substansi, 
mengubah perilaku dan kultur penggunanya secara signifikan, dan meningkatkan budaya komunikasi ilmiah dalam penerbitan jurnal. Hal tersebut merupakan salah satu bentuk mediatisasi dalam bidang penerbitan.

Hjarvard (2008) mengatakan bahwa dalam mediatisasi, media memiliki fungsi penting dalam proses mediasi dan menjadi bagian yang tak terpisahkan dari tatanan kehidupan sosial masyarakat. Keberadaan media akan membentuk perilaku dan budaya masyarakat, media bersifat independen dan institusional. Media sebagai representasi teknologi menjadi saluran/mediasi yang mengungkapkan realitas yang sedang atau telah terjadi. Realitasnya bahwa dalam mediasi, media akan mempengaruhi pikiran dan perilaku para aktor dan pengguna media. Mediasi melalui media (orang dan teknologi), eksistensinya nyata, dapat diterima secara logika. Realitas ini terbentuk karena ada aktor yang melembagakan logika media dalam kehidupan sosial. Misalnya dalam kehidupan ekonomi dan pemerintahan, media menginformasikan tren perkembangan ekonomi atau prediksi ancaman terhadap lingkungan/ keamanan nasional. Informasi yang disampaikan media tersebut akan diterima secara sadar oleh masyarakat, dan walhasil media akan membentuk wacana dan opini masyarakat yang berbeda-beda (Strömbäck, 2008). Berdasarkan uraian di atas, tulisan ini membahas tentang mediatisasi dari pemerintah terkait kebijakan penerbitan $e$-journal dengan aplikasi OJS di Indonesia.

Kajian ini menggunakan pendekatan deskriptif - kualitatif. Dengan pendekatan tersebut, peneliti merupakan bagian dari data, artinya peneliti ikut aktif dalam menentukan jenis data yang diinginkan - penelitian ini bersifat subjektif dan hasilnya lebih kasuistik bukan untuk digeneralisasikan (Kriyantono, 2006). Penelitian kualitatif merupakan tradisi tertentu dalam ilmu pengetahuan sosial, yang secara fundamental tergantung pada hasil pengamatan manusia dalam lingkungannya sendiri dan berhubungan dengan orang lain dalam bahasa dan peristilahannya (Setyawan, 2013). Melalui pendekatan kualitatif, penulis dapat menjelaskan suatu fenomena secara komprehensif berdasarkan pengetahuan dan pengalaman yang dimilikinya. Sumber data kajian ini adalah studi literatur dan pengetahuan best practice penulis sebagai pengelola e-journal yang menggunakan OJS. Untuk memperjelas data kualitatif, penulis menjabarkan pemahamannya secara deskriptif berdasarkan fenomena yang terkait dengan mediatisasi dalam penerbitan e-journal. Berdasarkan studi literatur dan pengetahuan best practice inilah penulis mengungkapkan bahwa ada praktik mediatisasi dari pemerintah, yaitu menetapkan OJS sebagai platform standar penerbitan $e$ - 
journal di Indonesia. Data yang terkumpul kemudian menjadi dasar penyusunan pembahasan dan kesimpulan kajian ini.

\section{B. HASIL DAN PEMBAHASAN}

\section{Mediatisasi dalam Penerbitan Jurnal}

Mediatisasi merupakan proses yang panjang dimana institusi budaya dan sosial saling berinteraksi sebagai konsekuensi dari pengaruh pertumbuhan media (Hjarvard, 2016). Konsep mediatisasi telah membuat dampak yang kuat pada studi media dan komunikasi, dan pembahasan konsep ini terpusat pada pengaruh media terhadap penggunanya (Ampuja, Koivisto, \& Väliverronen, 2014). Mediatisasi dapat dilakukukan secara langsung dan tidak langsung. Mediatiasi yang dilakukan secara langsung memiliki pengaruh yang kuat untuk mengubah kultur masyarakat. Pengguna media dapat secara langsung memahami dan mengetahui tentang hal yang harus dilakukan ketika memanfaatkan media media tersebut. Hal yang sama dikatakan Hjarvard (2008) mengatakan bahwa dalam mediatisasi langsung, ada penampakan dari fungsi media dalam sebuah aktivitas sosial yang akan menggantikan dan mengubah kultur masyarakat, yang awalnya tidak termediasi menjadi termediasi. Sedangkan mediatisasi yang tidak langsung, memiliki pengaruh yang kuat terhadap kultur masyarakat. Masyarakat akan percaya dari keberadaan dan fungsi media jika ia sudah benar-benar memperoleh manfaat setelah memanfaatkan media tersebut. Dalam mediatisasi tidak langsung, eksistensi dan pengaruh media tidak terlalu kuat mengubah kultur masyarakat, dan mereka hanya sebatas penikmat media.

Konsep mediatisasi selalu membawa konsekuensi, yang muncul dari proses transformasi komunikasi melalui media. Mediatisasi dirancang untuk menangkap hasil konstruksi komunikasi realitas yang dimanifestasikan dalam proses pada media tertentu, yang pada akhirnya fitur spesifik dari media tertentu memiliki 'konsekuensi' kontekstual untuk mempengaruhui proses keseluruhan dalam realitas sosial budaya (Couldry \& Hepp, 2013). Konsekuensi lainya adalah ketergantungan manusia dengan teknologi menyebabkan batas manusia dengan mesin semakin kabur. Sebagai gambaran, untuk mencari informasi perpustakaan, orang harus menggunakan katalog perpustakaan yang tersambung dengan internet agar informasi/koleksi yang dicari dapat ditemukan. Agar koleksi ditemukan, maka orang tersebut harus mengetahui bagaimana caranya mencari informasi di katalog perpustakaan, mulai dari penggunaan kata kunci (keyword) hingga pencatatan data koleksi di rak perpustakaan (Fatmawati, 2016). 
Dalam konteks tulisan ini, praktik mediatisasinya pada dunia penerbitan publikasi ilmiah, yaitu penerbitan e-journal menggunakan OJS. Praktik mediatisasi dilakukan pemerintah melalui kebijakan resmi sebagaimana yang terlah tercantum dalam Surat Edaran Dirjen RisbangDIKTI No.93/E/SE/XII/2015 tentang Akreditasi Jurnal Ilmiah Secara Elektronik, bahwa per- 1 April 2016, pemerintah hanya menerima dan memproses usulan akreditasi jurnal (terbitan berkala) ilmiah nasional yang telah dikelola secara elektronik; untuk memudahkan pengelolaannya, $e$ journal harus dikelola secara elektronik menggunakan OJS atau aplikasi pengelolaan e-journal lainnya. Praktik mediatisasi tersebut berpengaruh pada terhadap perubahan tampilan dan proses penerbitan jurnal, perubahan perilaku dan kultur pengguna, dan meningkatnya budaya komunikasi ilmiah dalam proses penerbitan jurnal.

\section{Jurnal Sebagai Publikasi IImiah}

Sebagian besar masyarakat ilmiah yang berkecimpung di dunia pendidikan dan penelitian menganggap jurnal sebagai publikasi ilmiah yang memiliki reputasi paling tinggi jika dibandingkan dengan publikasi lain seperti buku dan prosiding, karena informasinya yang mutakhir dan up to date serta dapat terindeks oleh pengindeks global seperti Scopus dan/atau Web of Science. Bagi personal, karya tulis di jurnal merepresentasikan identitas keilmuan/kepakaran seseorang. Bagi institusi, jurnal merepresentasikan identitas intelektual yang dilembagakan yang publikasinya akan selalu terjaga dan tersimpan dalam sebuah sistem repositori. Jurnal harus direpresentasikan ke dalam suatu media terbitan atau yang disebut sebagai publikasi agar keberadaannya dapat diketahui oleh masyarakat.

Sebagai publikasi, jurnal berisi tulisan yang mengandung informasi dan pengetahuan yang bersifat ilmiah (scientific). Ilmiah berarti bersifat ilmu; secara ilmu pengetahuan; memenuhi syarat (kaidah) ilmu pengetahuan (KBBI, 2016). Publikasi ilmiah sebagai salah satu bentuk kemajuan ilmu pengetahuan berfungsi sebagai motor penggerak pengembangan keilmuan masyarakat (Mukherjee, 2009). Sebagai publikasi ilmiah jurnal memiliki sifat keaslian (originality) dan keterbaruan (novelty) atas informasi iptek yang dikandungnya. Informasi iptek yang terkandung dalam jurnal memiliki karakteristik keberkalaan (periodical), yang disusun secara baku dan sistematik sesuai dengan pedoman penerbitan ilmiah yang berlaku. Selain itu, untuk memenuhi persyaratan administrasi sebagai publikasi ilmiah, jurnal harus memenuhi persyaratan, diantaranya memiliki nomor ISSN (cetak dan elektronik), terbit minimal 2 kali dalam setahun, memiliki editor dan 
reviewer, melalui proses review naskah, memiliki format standar dan sistematika penulisan yang baku,dan memperhatikan kaidah ilmiah yang lain.

Sebagai publikasi ilmiah, jurnal memiliki empat fungsi, yaitu sebagai media penghubung (conduits), bahasa (language), lingkungan (environment), dan literasi (literacy). Meyrowitz (1998) mengatakan bahwa sebagai penghubung, media berfungsi sebagai saluran (channel) tempat penyampaian media; sebagai bahasa, media berfungsi sebagai sebuah bahasa yang dikemas dengan bahasa media; dan sebagai lingkungan, media sebagai sesuatu yang dapat digunakan untuk mengkomunikasikan kebutuhan hidup kita dalam lingkungan sosial. Media ada di mana-mana, ketika kita berpikir, bertindak, dan berpakaian merupakan pengaruh dari media. Perilaku kita tergantung dari fungsi media tersebut dapat digunakan. Sebagai media literasi, jurnal berfungsi sebagai saluran interaksi dan pembawa pesan konten media untuk kebutuhan literasi (melek huruf dan tata bahasa) masyarakat. Anwar (2018) mengatakan untuk memahami konsep literasi, harus ada penggunaan variabel produksi pada setiap media tersebut.

\section{Mediatisasi OJS di Indonesia}

OJS yang dibangun oleh Public Knowledge Project (PKP) pada tahun 2001 manjadi awal kebangkitan industri penerbitan e-journal di dunia. OJS sebagai media penerbitan e-journal memberikan kemudahan bagi penggunanya tanpa dibatasi oleh ruang dan waktu. Konsep ruang dan waktu inilah yang menjadi prinsip efektivitas dan efisiensi penerbitan e-journal dengan OJS. Dengan OJS, setiap orang dapat: (1) memanfaatkan dengan mudah tanpa memiliki modal yang besar untuk meng-instal dan mengoperasikannya (karena open source dan server sistem cloud computing); (2) mengirim naskah tanpa biaya pos (manuskrip tanpa dicetak), penulis hanya perlu registrasi, login, dan submit naskah ke OJS melalui jaringan internet (hasil submit akan dinotifikasi via-email secara otomatis); (3) sistem editorial dan peer-review naskah meningkatkan budaya komunikasi ilmiah (penulis, editor, reviewer, proofreader) dapat saling bertanya dan berkomentar); (4) menghemat biaya penerbitan, publikasi, promosi, dan diseminasi jurnal secara massal ke masyarakat global; (5) meningkatkan webometrik lembaga secara nasional dan global (konten jurnal dianggap menjadi kontributor terbesar dalam peningkatkan reputasi ilmiah lembaga penelitian dan universitas melalui website).

Di Indonesia, implementasi OJS dimulai sejak tahun 2009 yang di mulai dari komitmen besar para inisiator OJS untuk menggerakan Open Access Journal (OAJ) nasional secara global. Pemerintah, dalam hal ini Pusat 
Dokumentasi dan Informasi Ilmiah - LIPI, dan Pusbindiklat Peneliti - LIPI, Ditlitabmas Kemenristek-Dikti sejak tahun 2009 telah melakukan berbagai kegiatan dalam upaya peningkatan kuantitas dan kualitas e-journal di Indonesia, diantaranya sebagai berikut.

- Melakukan penerjemahan dokumentasi OJS dan adopsi OJS ke bahasa Indonesia, serta menetapkan OJS sebagai aplikasi standar e-journal di Indonesia (2009).

- Pembuatan panduan penerbitan jurnal dengan OJS agar mudah dipahami oleh pengelola jurnal (2010).

- Pelatihan OJS dasar, mulai dari kebijakan, instalasi, manajemen situs, manajemen jurnal, dan penerbitan jurnal (2011 - 2012).

- Pelatihan OJS lanjutan, praktik secara online (2012 - 2016).

- Penyediaan literatur e-journal berlangganan, untuk bahan referensi primer dan mutakhir bagi penulis $(2010-2016)$.

- Pelatihan training of trainers (TOT) untuk penulisan artikel ilmiah (2009-2016).

- Penyusunan dan penetapan Pedoman Akreditasi Terbitan Berkala Ilmiah Elektronik (2014).

- Workshop internasionalisasi jurnal dan pemberian insentif jurnal terindeks $(2013-2014)$.

- Persiapan sistem Akreditasi Jurnal Nasional/ARJUNA (http://arjuna.dikti.go.id) dan pelatihan pengajuan akreditasi jurnal melalui sistem ARJUNA (2012).

- Persiapan Tim Nasional Akreditasi Terbitan Berkala Ilmiah (TBI) dan Tim Asesor Substansi dan Asesor Tatakelola TBI (2015).

- Pelatihan TOT dan Penyamaan Persepsi Asesor Akreditasi TBI (2015).

- Pemberian bantuan tata kelola jurnal elektronik (2015).

- Proses re-evaluasi dan monitoring TBI Terkraditasi (2017 - sekarang).

- Grading kualitas jurnal berdasarkan aturan akreditasi nasional (SINTA); Penghargaan penulis di Jurnal Internasional terindeks Scopus dengan sitasi dan impact factor terbanyak; Integrasi sistem akreditasi jurnal nasional (http://arjuna.ristekdikti.go.id/); Cloud Jurnal Elektronik (http://rujukan.lipi.go.id) (2018 - sekarang).

Gerakan OAJ ini sangat penting untuk meningkatkan produktivitas publikasi ilmiah peneliti Indonesia di dunia internasional yang selama ini dianggap masih sangat rendah, terutama publikasi di media jurnal ilmiah yang terindeks di pengindeks internasional bereputasi. Hal tersebut disebabkan karena budaya menulis yang belum berkembang di masyarakat, 
khususnya di perguruan tinggi, atau masih rendahnya kemauan dan kemampuan menulis hasil-hasil penelitian maupun pengabdian kepada masyarakat dalam terbitan berkala ilmiah yang bermutu. Pengembangan budaya dan kemampuan terutama motivasi menulis menjadi suatu tantangan dan permasalahan yang harus segera dapat diatasi. Berdasarkan alasan tersebut, pemerintah perlu mengupayakan adanya standarisasi dalam pengelolaan dan penerbitan e-journal di Indonesia menggunakan OJS.

\section{OJS Mengubah Tampilan Jurnal}

OJS yang merupakan salah satu produk open source untuk penerbitan e-journal telah mampu merubah tampilan jurnal secara signifikan. Pengaturan tampilan jurnal dengan OJS ini merupakan aspek teknis, karena terkait dangan mengoperasikan sistem, meng-update fitur dan menu, mengisi dan melengkapi informasi kebijakan penerbitan jurnal. Nashihuddin \& Aulianto (2016) mengatakan bahwa pengelola jurnal juga harus menetapkan format tampilan naskah jurnal sesuai dengan standar baku yang telah ditetapkan. Misalnya, untuk penerbitan jurnal dengan media cetak, pengelola dapat merujuk pada buku "Pedoman Penampilan Majalah Ilmiah Indonesia" terbitan Pusat Dokumentasi dan Informasi Ilmiah - Lembaga Ilmu Pengetahuan Indonesia tahun 2014. Secara umum, buku tersebut mengatur bagian jurnal dan tata cara penulisannya. Bagian jurnal ini mencakup halaman sampul, halaman judul, halaman daftar isi, halaman teks (artikel), lembar abstrak, dan halaman indeks. Terkait tata cara penulisannya, pengelola jurnal perlu memperhatikan judul/nama, volume, nomor, waktu terbit, ISSN, penanggungjawab, penerbit, suplemen, dan judul sirahan jurnal (Suwahyono, Purnomowati, \& Ginting, 2014). Kemudian, untuk penerbitan e-journal, pengelola jurnal dapat merujuk pada buku pedoman "Policy Brief: Kebijakan E-Journal, Akreditasi, Indeksasi, Sitasi, dan Internasionalisasi Jurnal di Indonesia" terbitan Direktorat Jenderal Riset dan Pengembangan Kementerian Riset, Teknologi dan Pendidikan Tinggi tahun 2016. Tampilan ini terkait dengan fitur, menu, dan informasi kebijakan penerbitan jurnal melalui OJS.

Tampilan jurnal di OJS ini dapat dimodifikasi dan didesain secara menarik sesuai kebutuhan pengelola jurnal. Pengelola jurnal dapat mengatur tampilan jurnal dalam aspek nama website, header, deskripsi website, dan informasi lainnya di website jurnal (Arief \& Handoko, 2017). Pengaturan kebijakan tampilan dan informasi penerbitan jurnal disesuaikan dengan standar penerbitan jurnal, misalnya terkait dengan judul jurnal (nama dan inisial), alamat redaksi, kebijakan penerbitan (hak akses, privasi, hak cipta, 
lisensi), header dan thema tampilan jurnal, peran pengguna, topologi jurnal, dan fitur informasi lainnya.

Berikut ini contoh tampilan jurnal cetak dan e-journal dengan nama jurnal yang sama (Gambar 1).

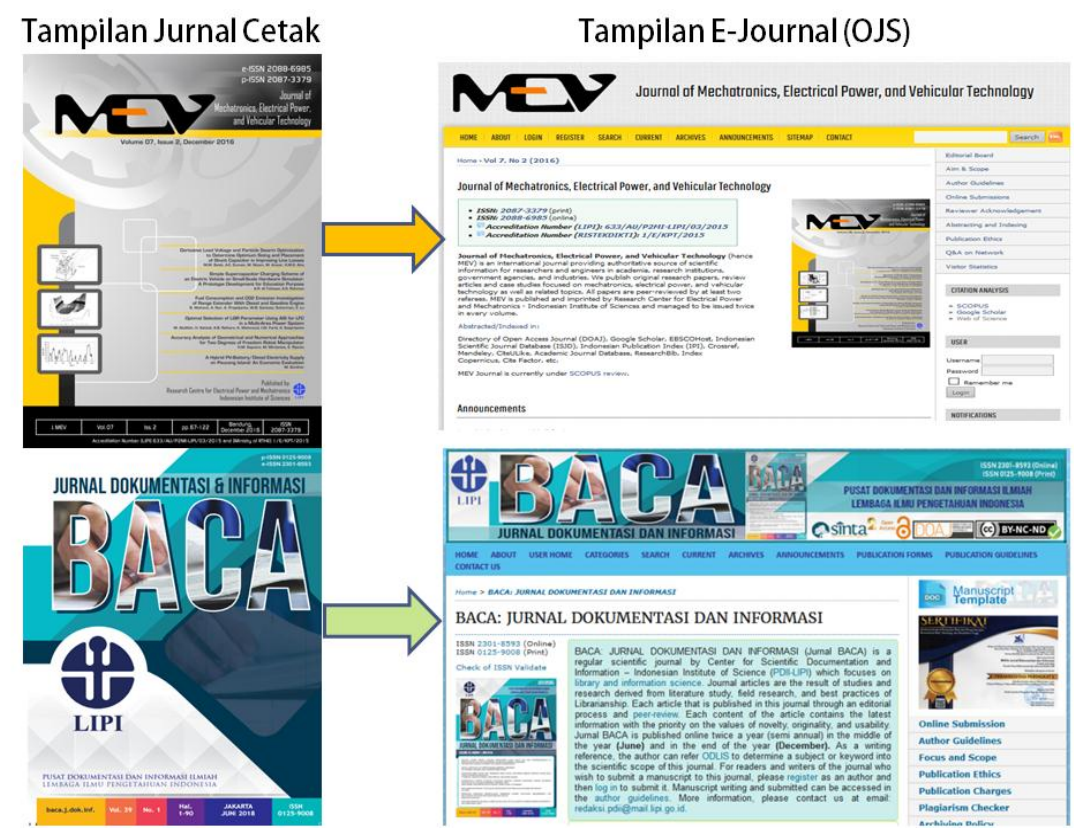

Gambar 1. Tampilan Jurnal Cetak dan E-Journal dengan OJS

Dalam mengatur tampilan jurnal, pengelola jurnal harus memiliki prinsip keramahan kepada pengguna (user friendly), kemudahan akses (accessibility), dan ketersedian konten (visibility), dinamis dan flesibel (flexibility). Dalam mengatur dan mendisain tampilan jurnal, seseorang setidaknya harus memiliki kemampuan dan ketrampilan teknis, seperti mengoperasionalkan aplikasi desain grafis (photoshop, coreldraw, indesign), pemilihan dan penggunaan warna website, pengaturan tampilan dalam format CSS, pemasangan hyperlink teks dan gambar, dsb. Hal tersebut dilakukan agar dalam pengaturan tampilan website jurnal lebih menarik dan interaktif.

\section{OJS Mengubah Proses Penerbitan Jurnal}

Secara prinsip bahwa mediatisasi membawa dampak perubahan pada perilaku dan kultur masyarakat, dalam hal ini adalah pengguna media. Hal yang sama juga berlaku dalam perilaku dan kultur pengguna OJS ketika melakukan penerbitan e-journal secara online. Pengguna OJS harus 
memahami tentang tahapan atau proses pengaturan web jurnal hingga penerbitan naskah/artikel jurnal (Gambar 2).

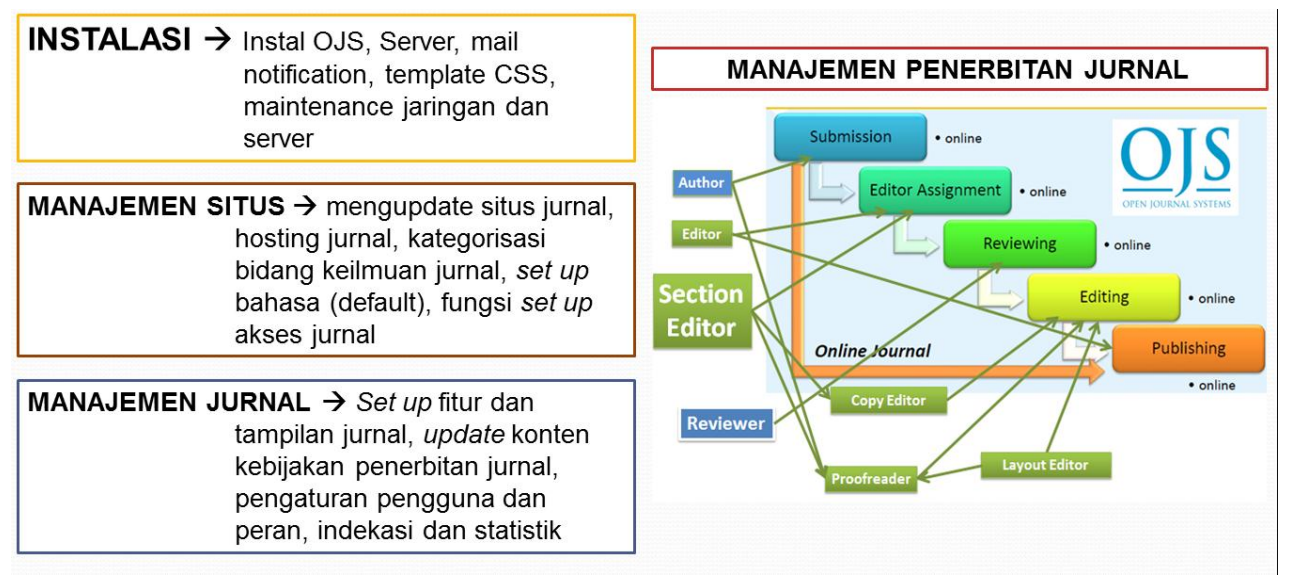

Gambar 2. Tahapan Penerbitan Artikel Jurnal dengan OJS

Dalam pengaturan web jurnal, pengelola harus berhasil melakukan instalasi sistem, pengaturan situs/website, pengaturan konten jurnal, dan penerbitan jurnal. Dalam proses penerbitan naskah jurnal, setiap pengguna harus memahami alur penerbitan yang diatur oleh OJS, mulai dari penulis (author) menyerahkan naskah ke editor - editor melakukan screening naskah kemudian mengirimnya ke editor bagian (section editor) - section editor mengirim naskah blind review ke reviewer - reviewer menelaah naskah dan memberikan rekomendasi apakah naskah layak diterbitkan atau tidak, dan mengirim kembali naskahnya ke section editor - section editor mengkonfirmasi hasil review naskah ke penulis - penulis merevisi naskah (jika ada catatan dari reviewer) - jika sudah direvisi, section editor mengirim naskah lengkap ke copy editor (untuk cek typo huruf, tata bahasa dan kalimat), layout editor (untuk mendesain naskah menjadi artikel jurnal), dan proofreader (untuk mengecek naskah akhir sebelum diterbitkan) - hingga editor menerbitkan artikel di website jurnal.

Selain itu, pengelola jurnal juga harus memahami alasan "mengapa ia harus menggunakan OJS untuk platform penerbitan jurnalnya?" ketika sudah menggunakan OJS, hal-hal apa saja yang harus dilakukan dan bagaimana mempraktikannya? dalam hal ini, pengelola harus memahami konsekuensi terhadap proses mediatisasi dalam penerbitan jurnal, di mana mereka (sebagai pengguna OJS) harus menyesuaikan diri dengan spesifikasi sistem OJS, sehingga dapat diterapkan di lembaganya. Misalnya dalam perspektif penerbitan jurnal melalui website, pengelola jurnal harus mampu 
membedakan antara "jurnal online" dengan "e-journal" yang secara proses sistem penerbitannya berbeda. Perbedaannya adalah penerbitan dalam jurnal online, tidak melalui aplikasi standar penerbitan jurnal, proses editorial dan review artikel lengkap (full text) tidak melalui OJS, dan editor langsung mengunggah artikel jurnal ke website (tidak harus menggunakan OJS). Sedangkan penerbitan dalam e-journal, proses penyerahan naskah oleh penulis, proses editorial naskah oleh editor, proses penelaahan naskah oleh review, dan penerbitan artikel jurnal editor semuanya melalui OJS, dan setiap prosesnya dapat dilihat rekam jejaknya (siapa yang mengerjakan dan kapan dikerjakan).

\section{E-Journal Sebagai Persyaratan Akreditasi}

Agar jurnal dapat terdiseminasikan secara luas maka harus dipublikasikan dalam bentuk elektronik (Dirjen Risbang, 2016). Penerbitan jurnal secara elektronik harus disediakan secara online sehingga dapat diakses oleh masyarakat luas. Sistem e-journal yang tersedia secara online ini harus diperhatikan oleh pengelola jurnal, karena akan memberikan beberapa keuntungan diantaranya: (1) mempelancar proses akreditasi jurnal ilmiah nasional; (2) meningkatkan webometrik lembaga; (3) meningkatkan jumlah sitasi penulis dan impact factor jurnal. Pemerintah (dalam hal ini Kemenristek-Dikti) sebagai pembuat regulasi dan kebijakan memiliki kuasa penuh untuk menetapkan proses bisnis organisasi dalam penerbitan $e$-journal dengan OJS, termasuk dalam hal persyaratan akreditasi jurnal ilmiah nasional.

Dalam mediatisasi OJS sebagai persyarakat akreditasi jurnal ilmiah nasional, penulis merujuk pada pernyataan kebijakan yang tercantum dalam Peraturan Menteri Riset, Teknologi, dan Pendidikan Tinggi Republik Indonesia Nomor 9 Tahun 2018 Tentang Akreditasi Jurnal Ilmiah, bahwa "jurnal ilmiah setidaknya dikelola dan diterbitkan secara elektronik melalui jejaring teknologi informasi dan komunikasi (Pasal 4); dan proses akreditasi jurnal ilmiah dilakukan secara elektronik melalui jejaring teknologi informasi dan komunikasi (Pasal 6)". Peraturan tersebut merepresentasikan adanya kebijakan yang harus dipatuhi bersama oleh pengelola jurnal ketika akan mengajukan akreditasi jurnal ilmiah nasional. Apabila jurnal tidak diterbitkan secara elektronik (e-journal) dan tidak dapat diakses secara online maka tidak dapat terakreditasi dan kualiatas penerbitannya dianggap kurang baik oleh komunitas ilmiah, dan sebaliknya.

Peraturan tersebut juga menyebutkan bahwa OJS sebagai platform standar penerbitan e-journal yang sangat direkomendasikan oleh pemerintah 
karena sistem ini dapat merekam sejarah setiap proses penerbitan jurnal secara lengkap dan jelas. OJS dianggap telah memenuhi persyaratan teknis dan manajerial untuk bahan evaluasi dan penilaian akreditasi secara online melalui database ARJUNA di http://arjuna.ristekdikti.go.id/ (Gambar 3).

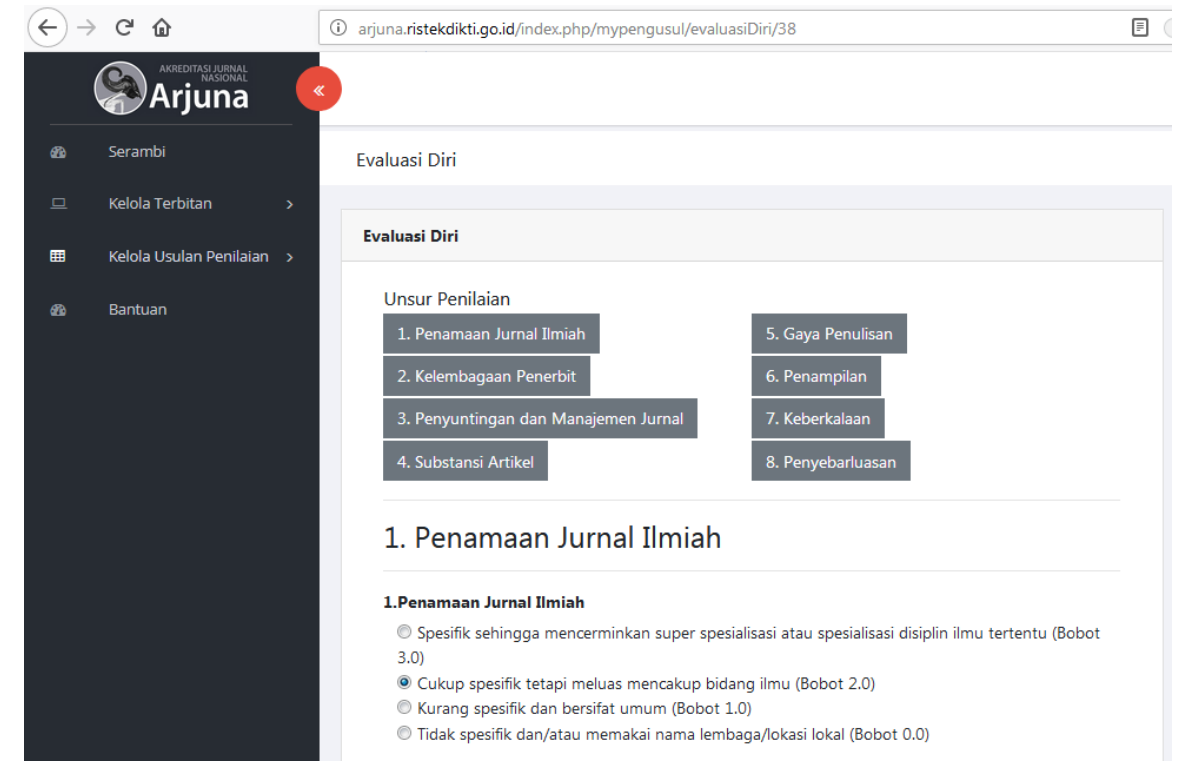

Gambar 3. Database ARJUNA untuk Akreditasi E-Journal N

Dalam proses penilaian jurnal melalui database ARJUNA, pengelola jurnal dapat terlebih dahulu melakukan evaluasi diri (self evaluation) sebelum pengajuan akreditasi ke tim asesor. Ketika evaluasi diri, pengelola jurnal harus memperhatikan delapan aspek, yaitu: (1) penamaan jurnal ilmiah, (2) kelembagaan penerbit, (3) penyuntingan dan manajemen jurnal, (4) substansi artikel, (5) gaya penulisan, (6) penampilan, (7) keberkalaan, dan (8) penyebarluasan (Kemenristekdikti, 2018). Hasil evaluasi diri terhadap kedelapan aspek tersebut menjadi dasar evaluasi dan penilaian kualitas jurnal oleh tim asesor akreditasi jurnal ilmiah nasional.

\section{Budaya Komunikasi Ilmiah}

Sahrudin (2019) mengatakan bahwa jurnal merupakan sarana komunikasi ilmiah, di mana publikasi ini memuat karya tulis ilmiah yang mengandung data dan informasi yang memajukan ilmu pengetahuan dan teknologi dan ditulis sesuai dengan kaidah-kaidah penulisan ilmiah serta diterbitkan secara berkala. Sebagai ilustrasi, dalam suatu proses penerbitan satu naskah/artikel jurnal terdapat peristiwa atau aktivitas interaksi antarpihak (penulis, editor, reviewer, proofreader) untuk berdiskusi dan 
berkomentar masalah kualitas substansi/isi naskah dari perspektif keilmiahan. Aspek yang dibahas biasanya terkait sistematika tulisan, kebaruan informasi naskah, kemutakhiran referensi yang digunakan untuk sitasi dan daftar pustaka, serta dampak penelitian bagi pembaca. Ketika menggunakan OJS untuk penerbitan naskah (e-journal), semua hasil diskusi dan komentar antarpihak akan terekam. Seperti pertanyaan penulis tentang "status naskah yang sudah di-submit, apakah sudah di-screening, di-edit, dan/atau di-review? Jika sudah, bagaimana hasil review-nya (diterima, direvisi, atau ditolak) dan jika diterima, kapan artikelnya dapat diterbitkan?". Dalam menanggapi pertanyaan penulis, editor juga dapat bertanya kembali ke penulis, "apakah naskah hasil review sudah direvisi? jika sudah, apakah dipastikan sudah sesuai saran/komentar reviewer?". Terkait dengan hasil review naskah, editor dapat bertanya ke reviewer, "apakah ada kendala dalam proses review naskah?", dan reviewer juga dapat bertanya kepada editor, "apakah ada perpanjangan waktu dalam proses review naskah, karena substansi naskah banyak catatan yang perlu direvisi oleh penulis?", begitu juga halnya dengan copy editor (tata bahasa naskah), layout editor (desain tampilan naskah dan jurnal), dan proofreader (pengecek naskah akhir sebelum terbit) juga ada interaksi guna menjaga konsistensi penerbitan (tampilan dan subtansi/isi) jurnal. Peristiwa dari berbagai aktivitas interaksi di atas merupakan rangkaian satu kesatuan yang dalam siklusi komunikasi ilmiah (karena output-nya adalah jurnal ilmiah yang dapat diakses secara online)

Hal tersebut sering dijumpai oleh setiap orang yang terlibat dalam penerbitan e-journal, bahkan melalui OJS-pun budaya komunikasi ilmiah akan tercipta dengan sendirinya. Pengembangan komunikasi ilmiah tidak terlepas dari upaya pengelola dalam melakukan tata kelola sumber daya elektronik berbasis teknologi. Sebagaimana dikatakan Mukherjee (2010) bahwa komunikasi ilmiah saat ini sudah beralih dari komunikasi lisan ke tulisan ke cetak dan terakhir ke elektronik/digital, dan e-journal merupakan salah satu bentuk kegiatan komunikasi ilmiah. Dalam konteks jaringan sosial di dunia virtual, komunikasi ilmiah akan mengkonstruksi interaksi sosialbudaya dalam sebuah social-networking - di mana terjadi interaksi sosial dalam ruang publik (public space), baik yang dilakukan secara face to face maupun dunia virtual (Mukhlis, 2019). Terkait hal tersebut, komunikasi ilmiah di dunia virtual, seperti adanya percakapan antar-pihak melalui email di OJS, sudah menjadi hal yang biasa dan akhirnya membudaya di kalangan mereka. Apabila komunikasi ilmiah sudah menjadi budaya, maka OJS sebagai media penerbitan $e$-journal berpengaruh besar terhadap perilaku dan kultur penggunanya. 


\section{KESIMPULAN}

Teknologi informasi dan komunikasi mempengaruhi fungsi media. Media yang awalnya hanya berfungsi sebagai alat/sarana (teknologi) kini berubah menjadi bagian penting dari kehidupan sosial, bahkan keberadaannya sangat mempengaruhi perilaku dan kultur masyarakat. Termasuk media yang digunakan dalam penerbitan jurnal. Jurnal sebagai identitas dan media publikasi ilmiah saat ini juga telah berganti medianya, dari jurnal cetak ke e-journal. Perubahan tampilan jurnal ini disebabkan karena adanya teknologi dan media yang digunakan untuk penerbitannya, dalam hal ini aplikasi OJS menjadi penyebab perubahan tampilan jurnal tersebut. Bahkan sejak tahun 2018, Pemerintah (Kemenristek-Dikti) telah menegaskan kebijakannya kembali bahwa jurnal ilmiah yang ingin terakreditasi secara nasional harus menggunakan OJS sebagai salah satu platform penerbitannya. Kebijakan pemerintah tersebut sangat menguatkan eksistensi dan fungsi OJS, yang awalnya hanya sebatas aplikasi untuk penerbitan e-journal kini telah menjadi media yang dilembagakan untuk merintis kebangkitan penerbitan open access journal di Indonesia dan menjadi salah satu persyaratan akreditasi jurnal ilmiah nasional. Ketika sudah dilembagakan, aplikasi OJS akan mengatur perilaku dan kultur penggunanya, serta meningkatkan budaya komunikasi ilmiah.

\section{DAFTAR RUJUKAN}

Ampuja, M., Koivisto, J., \& Väliverronen, E. (2014). Strong and weak forms of mediatization theory: A critical review. Nordicom Review, 35, 111124.

Anwar, K. (2018). Mediatisasi Rupa Kota dalam Iklan Meikarta. Lensa Budaya, 13(1), 75-83.

Arief, I., \& Handoko, H. (2017). Jurnal Online dengan Open Journal System. Padang: LPTIK Universitas Andalas.

Couldry, N., \& Hepp, A. (2013). Conceptualizing Mediatization: Contexts, Traditions, Arguments. Communication Theory, 23, 191-202. https://doi.org/doi:10.1111/comt.12019

De Silva, P. U. ., \& Vance, C. K. (2017). Scientific Scholarly Communication: The Changing Landscape. Springer, 8.

Dirjen Risbang, K. (2016). Policy Brief: Kebijakan E-Journal, Akreditasi, Indeksasi, Sitasi dan Internasionalisasi Jurnal di Indonesia. Jakarta. 
Fatmawati, E. (2016). Perubahan Kultur Akses Informasi Pemustaka Dalam Bingkai Mediasi dan Mediatisasi. Semarang.

Hjarvard, S. (2008). The Mediatization of Society: A Theory of the Media as Agents of Social and Cultural Change. Nordicom Review, 29(2), 105134.

Hjarvard, S. (2016). Medialisering: Teori og Historie. In S. Hjarvard (Ed.), Medialisering. Mediernes Rolle i social og Kulturel Forandring (pp. 17-38). København: Hans Reitzel.

KBBI, I. (2016). Kamus Besar Bahasa Indonesia. Retrieved October 9, 2019, from Jakarta: Kementerian Pendidikan dan Kebudayaan Republik Indonesia website: https://kbbi.kemdikbud.go.id/entri/karakter

Kemenristekdikti, I. Peraturan Menteri Riset, Teknologi, dan Pendidikan Tinggi Republik Indonesia Nomor 9 Tahun 2018 Tentang Akreditasi Jurnal Ilmiah. , (2018).

Kriyantono, R. (2006). Teknik Praktis Riset Komunikasi. Jakarta: Kencana Prenada Media Group.

Lukman, L., Ahmadi, S. S., Manalu, W., \& Hidayat, D. S. (2017). Pedoman Publikasi Ilmiah. Jakarta: Direktorat Jenderal Penguatan Riset dan Pengembangan - Kementerian Riset, Teknologi, dan Pendidikan Tinggi.

Lukman, L., Hidayat, D. S., \& Atmaja, T. D. (2016). Manajemen Jurnal Elektronik (e-Journal). Depok.

Meyrowitz, J. (1998). Multiple Media Literacies. Journal of Communication, 48(1), 96-108. https://doi.org/10.1111/j.1460-2466.1998.tb02740.x

Mukherjee, B. (2009). Scholarly Communication: A Journey from Print to Web. Library Philosophy and Practice.

Mukherjee, B. (2010). Scholarly Communication in Library and Information Services: The Impacts of Open Access Journals and E-Journals on a Changing Scenario. London: Chandos Publishing.

Mukhlis, M. (2019). Pengembangan Komunikasi Ilmiah dalam Pengelolaan Repositori Institusi: Studi Kasus pada Tiga Perpustakaan Universitas di Yogyakarta (UGM, UNY, dan UIN Sunan Kalijaga). Yogyakarta.

Nashihuddin, W., \& Aulianto, D. R. (2016). Pengelolaan Terbitan Berkala Ilmiah Sesuai Ketentuan Akreditasi: Upaya Menuju Jurnal Trakreditasi 
dan Bereputasi Internasional. Jurnal Pustakawan Indonesia, 15(1-2), 83-98.

Sahrudin, U. (2019). Peran Pustakawan Dalam Pengelolaan Dan Penerbitan Jurnal Ilmiah (Role Of Library In Management And Publishing Scientific Journals). Kandaga - Media Publikasi Ilmiah Jabatan Fungsional Tenaga Kependidikan, 1(1).

Setyawan, S. (2013). Konstruksi Identitas Suporter Ultras di Kota Solo (Studi Fenomenologi terhadap Kelompok Suporter Pasoepati Ultras). Surakarta.

Strömbäck, J. (2008). Four Phases of Mediatization: An Analysis of the Mediatization of Politics. 13(3), 228-246. https://doi.org/10.1177/1940161208319097

Suwahyono, N., Purnomowati, S., \& Ginting, M. (2014). Pedoman Penampilan Majalah Ilmiah Indonesia. Jakarta. 